\title{
A concept of a new AFIS tool for automated data record
}

\section{Jakub Nosek ${ }^{1 *}$, Petr Lukeš ${ }^{1}$}

${ }^{1}$ Czech Technical University in Prague, Faculty of Transportation Sciences, Prague, Czech Republic

*Corresponding author: Czech Technical University in Prague, Faculty of Transportation Sciences, Horská 3, 12801 Prague, Czech Republic, Email: nosekja6@fd.cvut.cz

\begin{abstract}
AFIS officers are mandated by the Czech Annex L11, Appendix $N$ regulation to record specified information about all landings and take-offs at AFIS airports. This task is currently being done manually by the officers. The paper describes a possible usage of a software tool which could help Aerodrome Flight Information Service officers to perform their duties more efficiently. It is focused on the solution to, in full measure, record this mandatory information automatically without the officers' intervention. The result of the study is a set of information that could be recorded automatically with suggested approach of how this can be performed.
\end{abstract}

\section{Keywords}

AFIS, AFIS Officer, ADS-B, MLAT, Mode S

\section{Introduction}

The requirements for provision of the Aerodrome Flight Information Service in the Czech Republic are stated in the Appendix $\mathrm{N}$ of the Czech Annex L11 regulation, which is an equivalent of the international ICAO Annex 11. One of the requirements contained in Appendix N, AFIS officers must comply with, is a requirement 2.5.2. This requirement mandates the AFIS officers to maintain a register of all takeoffs and landings at a given AFIS airport. [1] The following information must be recorded for each aircraft:

- Date and time of take-off/landing.

- Aircraft registration.

- Name of the command pilot.

- Number of people on-board the aircraft.

Currently, the AFIS officers must record this information manually, which can, especially at busy airports, distract their attention from more critical tasks, such as providing pilots with information about nearby air traffic. Therefore, one method of how some of this mandatory information could be recorded automatically using a software tool is proposed in this paper.

\section{Materials and Methods}

The solution for the automatization process is being discussed and consulted with Prague Letnany Airport, which is an AFIS airport with high traffic volume and therefore it could benefit from using such a tool. Since it is necessary to know the aircraft position for the purposes of determining whether the aircraft is airborne or on-ground in order to make a correct record in the register, the solution must comprise not only from a software part, but also from a hardware part- surveillance sensors.

It was decided to install a low-cost $1090 \mathrm{MHz}$ receiver at the airport. This kind of receiver can process all messages 
Table 1. Extended Squitter Type Codes

\begin{tabular}{ll}
\hline Type Code & ES Message \\
\hline $1-4$ & Aircraft Identification Squitter \\
$9-18,20-22$ & Airborne Position Squitter \\
19 & Airborne Velocity Squitter \\
$5-8$ & Surface Position Squitter \\
\hline
\end{tabular}

transmitted from aircraft equipped with a Mode A/C or Mode $\mathrm{S}$ capable transponder.

There is a large international airport near the Prague Letnany Airport where a secondary surveillance radar is installed and thus it is expected that all aircraft around the area are sufficiently interrogated on RF $1030 \mathrm{MHz}$. Therefore, there should be no issue with receiving a non-ADS-B Mode A/C or Mode $S$ downlink format (DF) replies. To determine whether the observed aircraft had landed or taken off, it is necessary to utilize the DF replies because they contain the aircraft position and other information encoded in the particular data fields.

The surveillance infrastructure could be easily extended in the future by adding at least three additional $1090 \mathrm{MHz}$ receivers to form a multilateration surveillance system. This would enable to determine the aircraft position independently of the data encoded in the DF messages.

\subsection{Determining the aircraft airborne/on-ground sta- tus}

For the purpose of determining whether the aircraft had landed or taken off it is necessary to determine its airborne/on-ground status by decoding the received downlink format messages. This can be done for two cases - aircraft equipped with an ADS-B OUT capable Mode S transponder as well as for aircraft equipped with a Mode $\mathrm{S}$ capable transponder without the ADS-B OUT capability.

\subsubsection{ADS-B OUT capable aircraft}

Aircraft with the ADS-B OUT capability shall transmit at least 3 standard extended squitter messages when it is reported airborne (Aircraft Identification Squitter, Airborne Position Squitter, Airborne Velocity Squitter) and 2 standard extended squitter messages when it is reported on-ground (Aircraft Identification Squitter and Surface Position Squitter). [2, 3] These extended squitter messages are distinguished by the Type Code, which is a 5-bit field placed in bits 33-37 of each extended squitter message. [3] The type codes for the abovementioned messages are listed in the following table.

Considering the different type code values used for each extended squitter message, it is possible to determine whether the aircraft is reported airborne or on-ground. When either $5,6,7$ or 8 type code value is received, the aircraft can be considered as on-ground. [2, 4] On the other hand, the aircraft can be considered as airborne if the type code values used for Airborne Position Squitter commenced to be transmitted instead of the Surface Position Squitter type code values. [2, 4] Both Airborne Position Squitter and Surface Position Squitter messages are transmitted twice per second and thus it is possible to determine the airborne/on-ground aircraft status early enough for this purpose. [4]

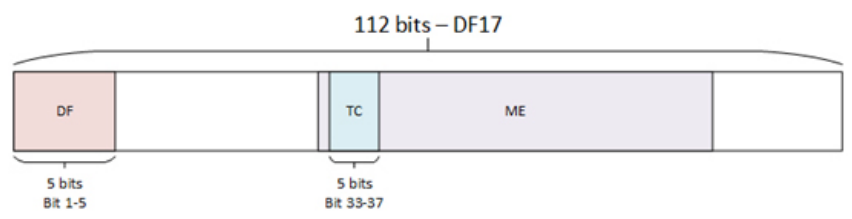

Figure 1. Type Code field location in the Extended Squitter message

\subsubsection{Aircraft without the ADS-B OUT capability}

In case it is not possible to determine the aircraft airborne/onground status by decoding of the ADS-B extended squitter messages Type Code values, a decoding of other downlink format messages transmitted on RF $1090 \mathrm{MHz}$ must be performed. In this case, the airborne/on-ground status information is reported in the Flight Status or Vertical Status fields of some DF messages. [4]

Flight Status (FS) This 3-bit field is contained in the following messages: DF4, DF5, DF20 and DF21. If either 1 or 3 values are encoded in the field, the aircraft reports on-ground status. If other values are present in the field, the aircraft can be considered airborne. [5, 6, 4]

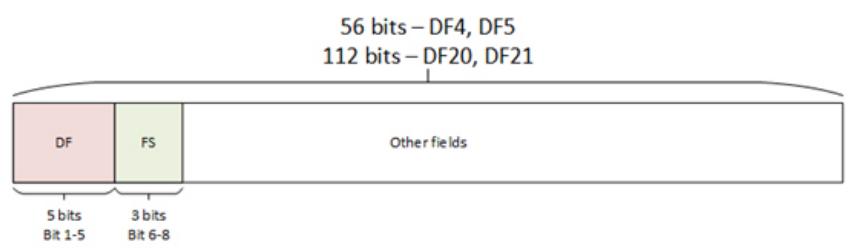

Figure 2. Flight Status field location in the DF messages

Vertical Status (VS) This 1-bit field is contained in the following messages: DF0 and DF16. If 1 is contained in the field, the aircraft reports on-ground status while if 0 is contained in the field, the aircraft reports airborne status. $[5,6,4]$

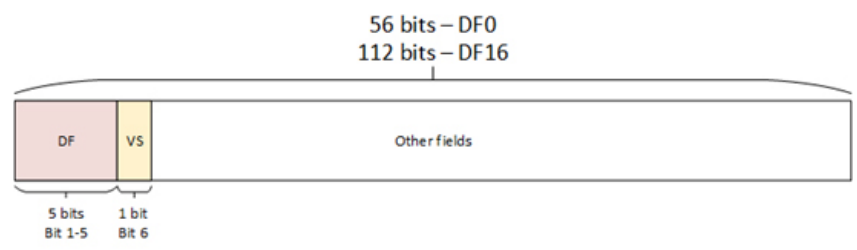

Figure 3. Vertical Status field location in the DF messages

\subsection{Determining the aircraft registration}

The aircraft registration can be directly determined only if the aircraft is equipped with an ADS-B OUT capable transponder. 
This information may be encoded in the Aircraft Identification Squitter; however, transponders should encode the aircraft registration in this extended squitter message only if a flight number as stated in a flight plan is not available. [3] Therefore, the AFIS officer would need to check and decide whether the encoded information is an aircraft registration or a flight number. If the aircraft is not equipped with an ADS-B OUT capable transponder, it is not possible to decode the aircraft registration as it is not encoded in any of the Mode S DF messages.

Another method of determining the aircraft registration is to decode the aircraft 24-bit Mode S address, which is contained in every Mode S DF message. [5, 6] This address is unique for each aircraft. Hence, getting access to the Mode $\mathrm{S}$ addresses database would enable to indirectly determine the aircraft registration by assigning it to the decoded Mode $\mathrm{S}$ address.

\subsection{Determining the date and time of landing and take-off}

The $1090 \mathrm{MHz}$ receiver used for receiving of the Mode A/C and Mode $\mathrm{S}$ messages is equipped with a GPS receiver. Therefore, a GPS time of signal arrival is attached to each message and thus the time when the airborne/on-ground aircraft status changed can be determined.

\section{Discussion}

Collecting information about the aircraft airborne/on-ground status, date and time of landing/take-off and aircraft registration for AFIS purposes can be performed automatically by decoding of the received messages. However, name of the command pilot and the number of people on board the aircraft are not present in the messages that can be received by the $1090 \mathrm{MHz}$ receivers. [5] This two information will need to be recorded manually by the AFIS operators based on other data that had been recorded automatically.

\section{Conclusion}

Appendix $\mathrm{N}$ of the Czech Annex L11 regulation mandates AFIS officers to maintain a register of information about aircraft movements at particular AFIS airport. This is currently being done manually and thus it distracts AFIS officers' attention from more critical tasks, such as providing pilots with information about nearby traffic.

This article proposed a solution to automatically record some data that are mandated to be recorded by the AFIS officers.

The limitation of the proposed solution is that it requires aircraft to be equipped with at least a Mode S capable transponder. A part of this limitation could be solved by adding three more $1090 \mathrm{MHz}$ receivers and applying a multilateration localisation principle. Using such an approach would enable to determine landings/take-offs of Mode A/C only transponder equipped aircraft and Mode $\mathrm{S}$ transponder equipped aircraft independently of the encoded information in the surveillance messages. However, other mandatory information would have to be added by AFIS officers manually anyway.

In any case, it has been explained in the article that some information which is mandated in the regulation can be recorded automatically if at least a low-cost surveillance infrastructure is installed at the airport and if aircraft are equipped with a Mode A/C or Mode S transponder.

\section{Acknowledgements}

This paper was supported by the Grant Agency of the Czech Technical University in Prague, grant No. SGS19/130/OHK2/2T/16.

\section{References}

[1] Předpis L-11, Appendix N - Letištní letová informační služba (AFIS), 2019. URL https://aim.rlp. cz/predpisy/predpisy/dokumenty/L/L11 /index.htm.

[2] Minimum Operational Performance Standards for 1090 $\mathrm{MHz}$ Automatic Dependent Surveillance - Broadcast (ADS-B), 2000.

[3] J. Nosek, S. Pleninger, and V. Socha. Analysis of real airborne collision avoidance system surveillance parameters. In 2019 IEEE 17th World Symposium on Applied Machine Intelligence and Informatics (SAMI), pages 17-22, Jan 2019. doi: 10.1109/SAMI.2019.8782728.

[4] Clarification - Mode S Transponder in an Airport/ASMGCS Environment, 2005.

[5] Minimum Operational Performance Standards for Air Traffic Control Radar Beacon System/Mode Select (ATCRBS/Mode S) Airborne Equipment, 2001.

[6] Minimum Operational Performance Standards for Traffic Alert and Collision Avoidance System II (TCAS II), Volume I, 2008. 